\title{
The negative impact of sugar-sweetened beverages on children's health: an update of the literature
}

\author{
Sara N. Bleich ${ }^{1 *}$ and Kelsey A. Vercammen ${ }^{2}$
}

\begin{abstract}
While sugar sweetened beverage (SSB) consumption has declined in the last 15 years, consumption of SSBs is still high among children and adolescents. This research synthesis updates a prior review on this topic and examines the evidence regarding the various health impacts of SSBs on children's health (overweight/obesity, insulin resistance, dental caries, and caffeine-related effects). We searched PubMed, CAB Abstracts and PAIS International to identify cross-sectional, longitudinal and intervention studies examining the health impacts of SSBs in children published after January 1, 2007. We also searched reference lists of relevant articles. Overall, most studies found consistent evidence for the negative impact of SSBs on children's health, with the strongest support for overweight/obesity risk and dental caries, and emerging evidence for insulin resistance and caffeine-related effects. The majority of evidence was crosssectional highlighting the need for more longitudinal and intervention studies to address this research question. There is substantial evidence that SSBs increase the risk of overweight/obesity and dental caries and developing evidence for the negative impact of SSBS on insulin resistance and caffeine-related effects. The vast majority of literature supports the idea that a reduction in SSB consumption would improve children's health.
\end{abstract}

Keywords: Sugar-sweetened beverages, Children's health

\section{Background}

Sugar sweetened beverages (SSB) - which include drinks with added sugar such as soda, fruit drinks and energy drinks - are frequently consumed by children and adolescents in the United States (U.S.) [1]. There is evidence that consumption of SSBs has recently begun to decline in the U.S., with this decrease largely driven by fewer children consuming these beverages [2, 3]. From 2003 to 2014, the percentage of children in the U.S. consuming at least one sugar-sweetened beverage on a typical day declined significantly from $80 \%$ to $61 \%$ [3]. Much of this decline was driven by a decrease in the percentage of young children ages 2 to 5 consuming SSBs, although the decline was significant for all age groups. Over the same period, consumption from caloric beverages (SSBs, milk and 100\% juice) declined from 463 to 296 daily calories, and the fraction of all beverage calories from

\footnotetext{
* Correspondence: sbleich@hsph.harvard.edu

'Department of Health Policy and Management, Harvard T.H. Chan School of Public Health, Boston, MA, USA

Full list of author information is available at the end of the article
}

SSBs decreased from $49 \%$ to $45 \%$ [3]. Within SSBs, the number of calories from soda and fruit drinks consumed per day declined from $116 \mathrm{kcal}$ to $49 \mathrm{kcal}$ and $70 \mathrm{kcal}$ to $31 \mathrm{kcal}$, respectively [3]. Despite these important declines, consumption of SSBs by children and adolescents in the U.S. still remains high. In 2013-2014, 46.5\% of children aged $2-5,63.5 \%$ of children aged $6-11$ and $65.4 \%$ of adolescents aged $12-19$ reported consuming at least one SSB on a given day [3]. Additionally, high levels of SSB consumption persist among low-income and racial and ethnic minorities.

In light of the frequent consumption of SSBs among children and adolescents in the U.S., there has been an interest in critically examining associated health consequences. As a result, there has been a substantial rise in the number of studies investigating the health effects of SSBs over the past decade. Evidence has emerged linking SSB consumption to a number of health consequences among adults including weight gain $[4,5]$, cardiovascular risk factors (e.g., dyslipidemia) [6], insulin resistance and type 2 diabetes $[7,8]$ and non-alcoholic fatty liver 
disease [9]. Studies among children are more limited and have generally focused on weight gain [4] and dental caries [10], as well as insulin resistance to a lesser extent $[11,12]$. An emerging body of research has also examined the association between caffeinated SSBs (e.g., energy drinks or colas) and caffeine-related health consequences including reduced sleep quality and headaches [13]. Given the growing number of studies assessing SSBrelated health consequences, concise summaries of the evidence base are needed in order to inform policy and advocacy efforts focused on reducing SSB consumption.

This review aims to synthesize the existing evidence regarding the impact of SSB consumption on children's health. Unlike previous reviews which have been limited in scope (e.g., focusing on a single outcome such as weight gain) [14, 15], this review summarizes evidence from cross-sectional, longitudinal and intervention studies on a broad range of health outcomes relevant to children including: obesity, insulin resistance, dental caries, and caffeine-related effects. A previous review published in 2009 summarized many early studies on SSBs and children's health [16]. Using a narrative review approach, we update the literature by reviewing more recent studies published up until 2017.

\section{Search selection}

For each of the health impacts (obesity, insulin resistance, dental caries and caffeine-related effects), separate searches were conducted of PubMed, Web of Science and PAIS International. For all searches, a search hedge was created in three parts: 1) terms relevant to SSBs including "beverage" and "sodas", 2) terms restricting to children and adolescents including "pediatric" and "teens" and 3) terms specific to the outcome being examined such as "body mass index" and "body weight" for the search on overweight and obesity risk (see Additional file 1: Appendix for full list of search terms). These search terms were chosen to retrieve the most relevant results using an iterative process in consultation with a medical librarian. For searches of PubMed, MeSH subject headings were used. In addition to database searches, reference lists of SSB reviews and articles were searched. Following the removal of duplicate studies, one author (K.V.) screened titles, abstracts and full-texts and another author (S.B.) confirmed the inclusion of these studies. Included studies had to be peer-reviewed articles examining the effects of SSBs on a specific health outcome, be limited to children and adolescents, and be published after January 1, 2007. We selected 2007 as the start date because the most recent relevant review [16] included studies published prior to this. Studies were excluded if they were not published in English, were not conducted in high-income countries (defined as membership in Organisation for Economic
Co-operation and Development) or were grey literature. We limited our scope to high-income countries to promote generalizability of results.

\section{Effects of SSBs on health outcomes in children Overweight and obesity risk}

A large number of studies have reported on the association between SSB consumption and overweight/obesity risk, with the majority of a cross-sectional [17-35] or longitudinal design [36-54] and only a few intervention studies (Table 1).

\section{Cross sectional studies}

Most cross-sectional studies found significant positive associations between SSB intake and obesity risk among children and adolescents $[17-19,21-25,27,29-32,34$, 35, 55]. For example, among 12 to 19 year olds in the 1999-2004 National Health and Nutritional Examination Survey (NHANES), each additional SSB serving $(250 \mathrm{~g})$ consumed per day was associated with a $0.93-$ percentile increase in Body Mass Index (BMI) z-score [34]. These positive findings were well-replicated across a range of OECD countries, including Canada, Spain, Greece and in Australia where those who consumed more than one SSB servings ( $\geq 250 \mathrm{~g}$ ) per day were $26 \%$ more likely to be overweight or obese compared to those who consumed less than one serving per day [27]. They are also consistent with results focused on specific subgroups such as among Mexican-American children aged 8-10 years where each additional SSB serving $(240 \mathrm{~mL})$ per week was associated with a 1.29 greater odds of obesity [17] and among toddlers living in low-income families where no SSB intake was associated with a $31 \%$ lower obesity prevalence compared to households where toddlers consumed two or more SSB servings (serving = 12 fluid ounces) per day [23].

Some of the cross-sectional studies found positive associations only within subsets of the sample $[18,19$, $21,29,32,35,55]$, including: boys [32, 35], boys aged 6 to 11 [21], children aged 9 to 11 [29], and among Mexican-American and non-Hispanic White adolescents only [18].

A small number of cross-sectional studies reported null findings $[20,26,33]$, and one study conducted in Korea among 9 to 14 year olds reported an inverse association among males [28].

\section{Longitudinal studies}

Like the cross-sectional data, longitudinal studies generally demonstrated that increased SSB consumption was associated with weight-related outcomes among children and adolescents [38, 39, 47-49, 51, 53, 56]. For example, among a nationally representative survey of 2 to 5 year olds in the U.S., children who consumed more than one 


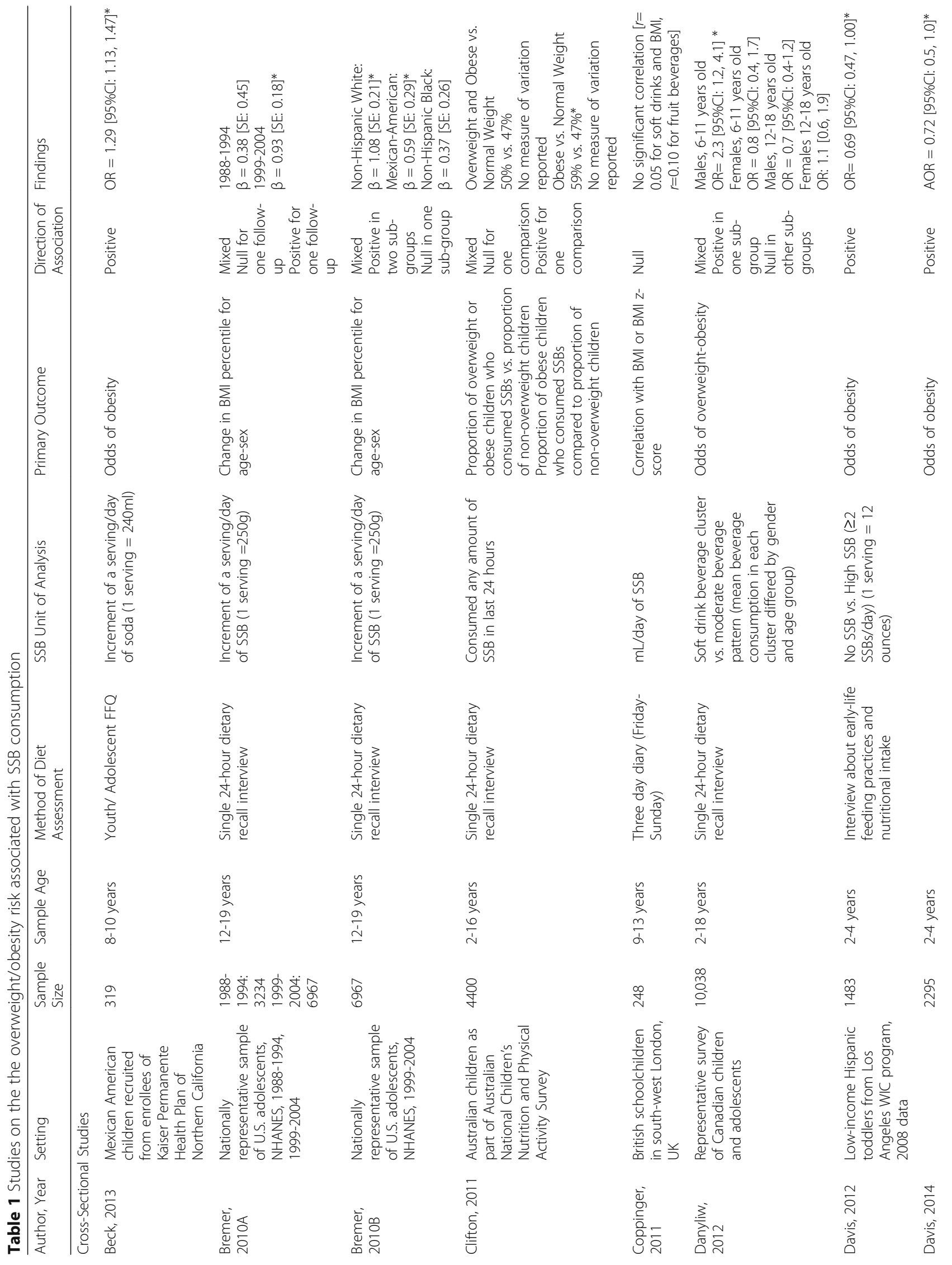




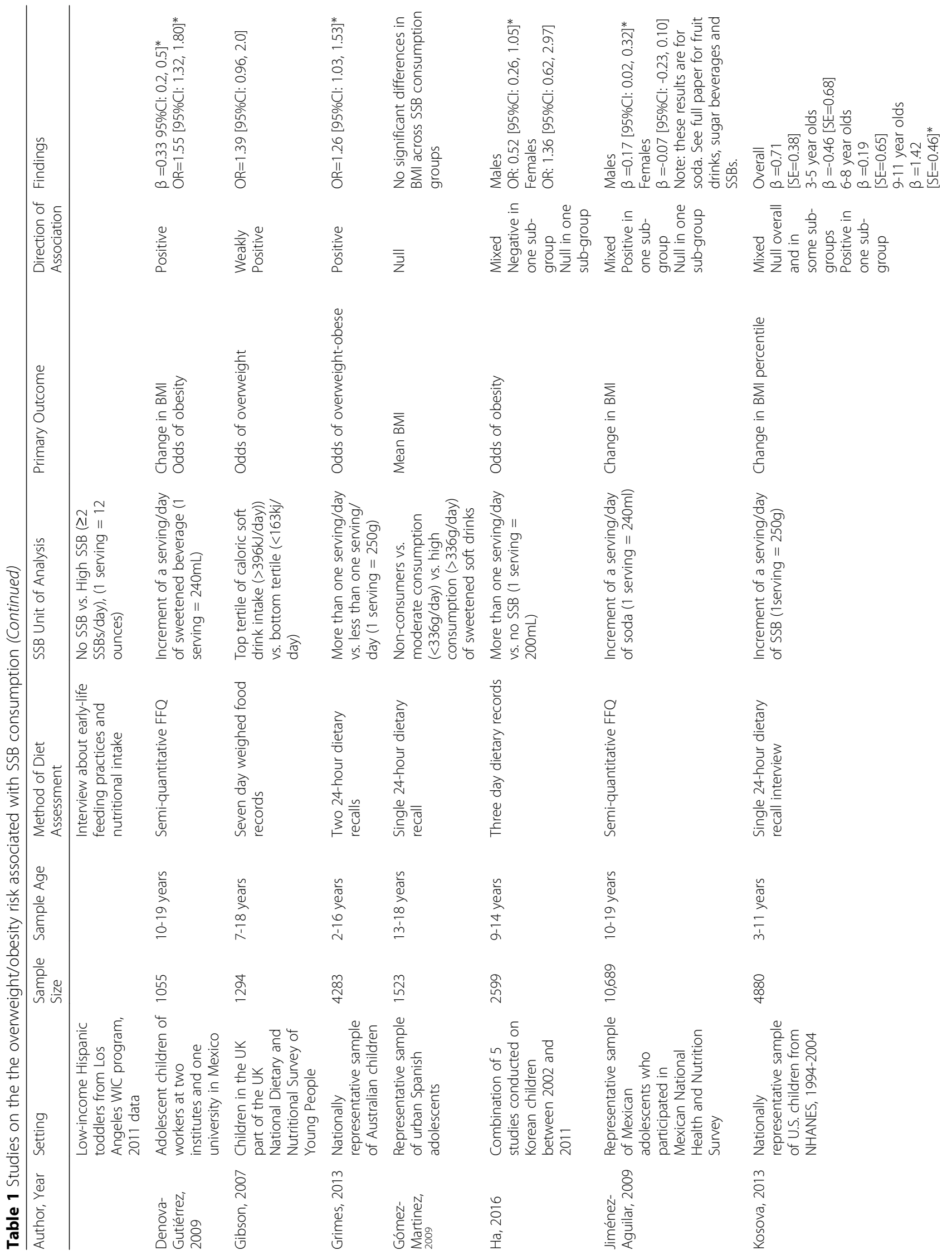




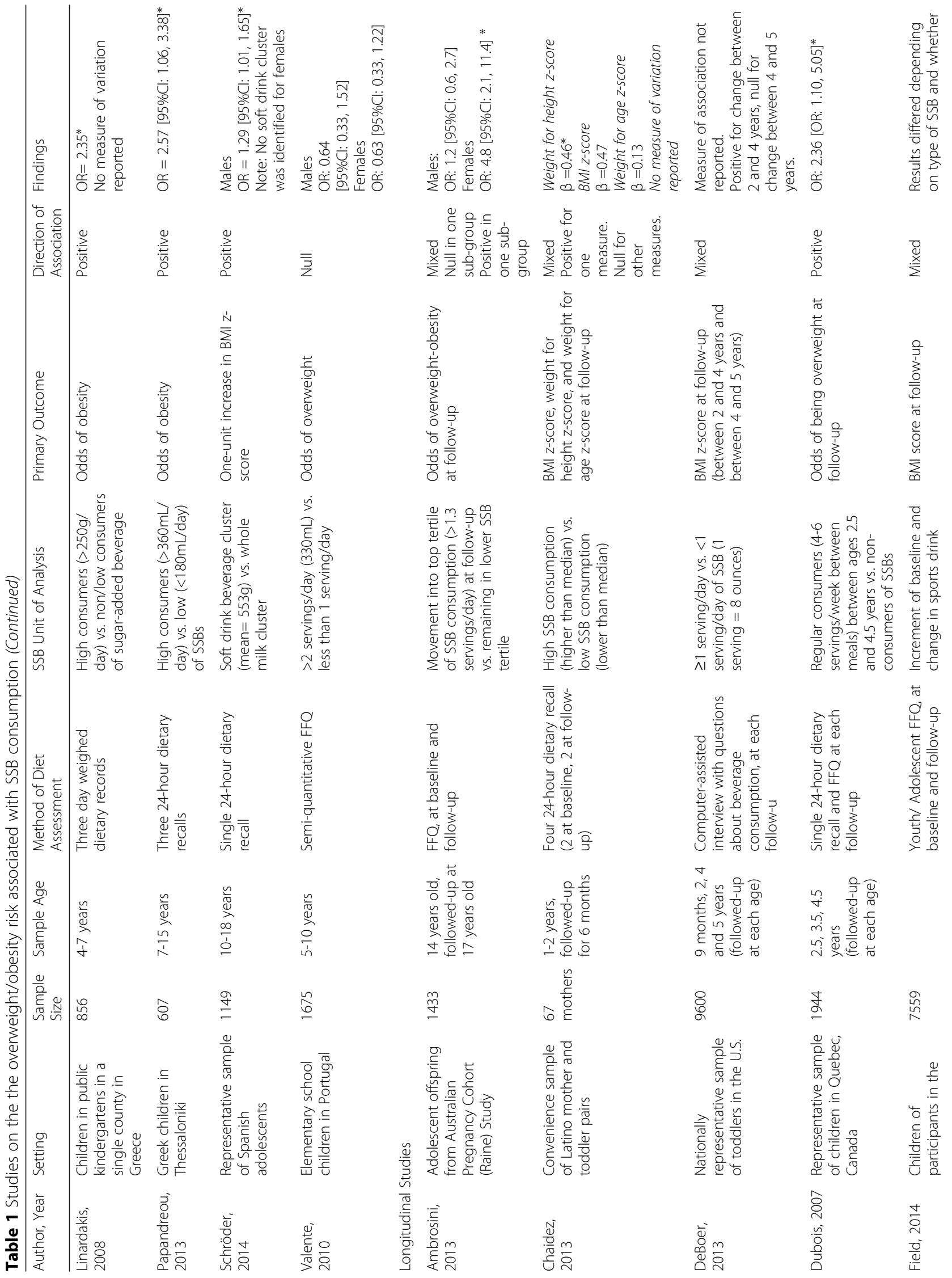




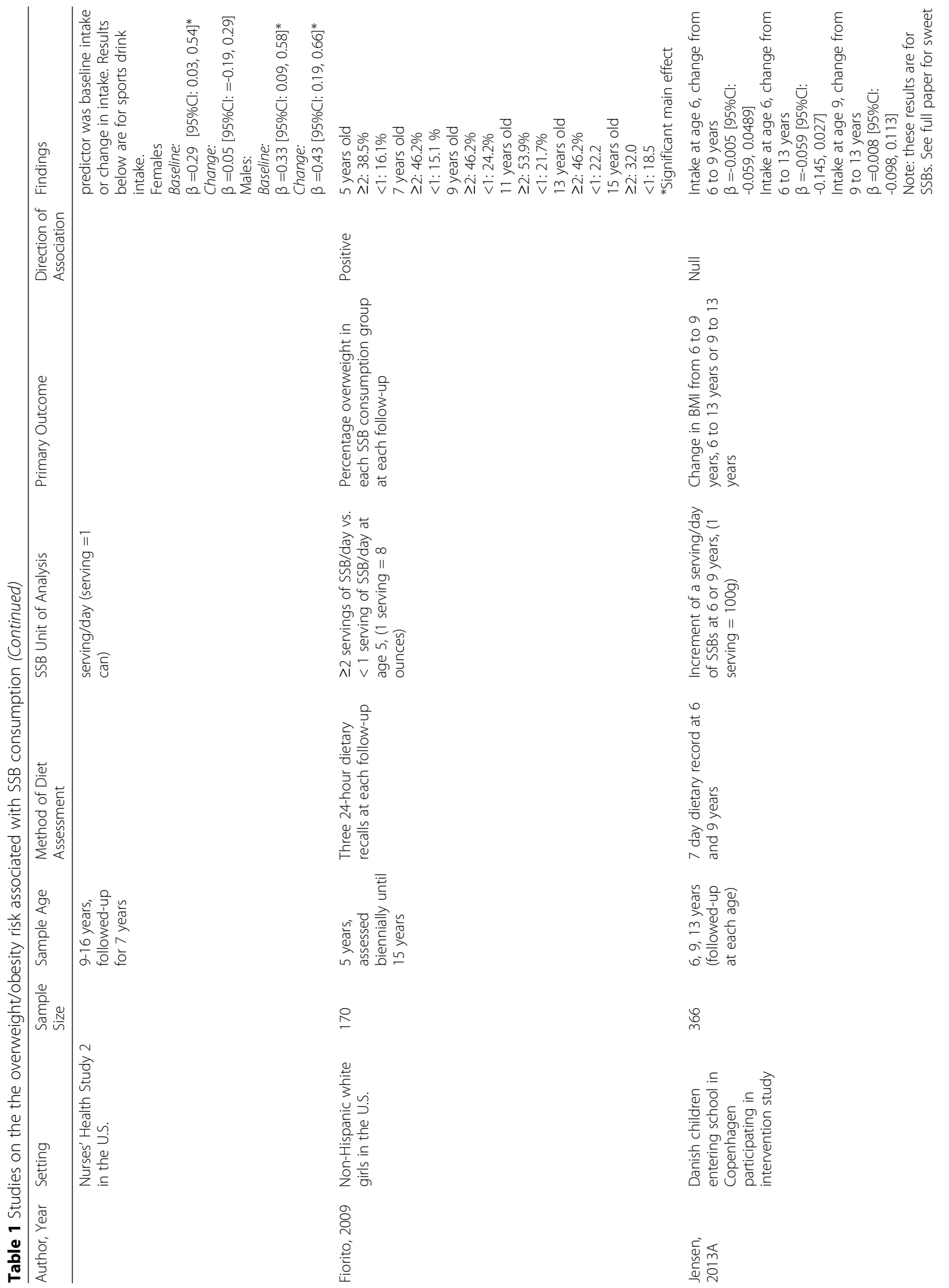




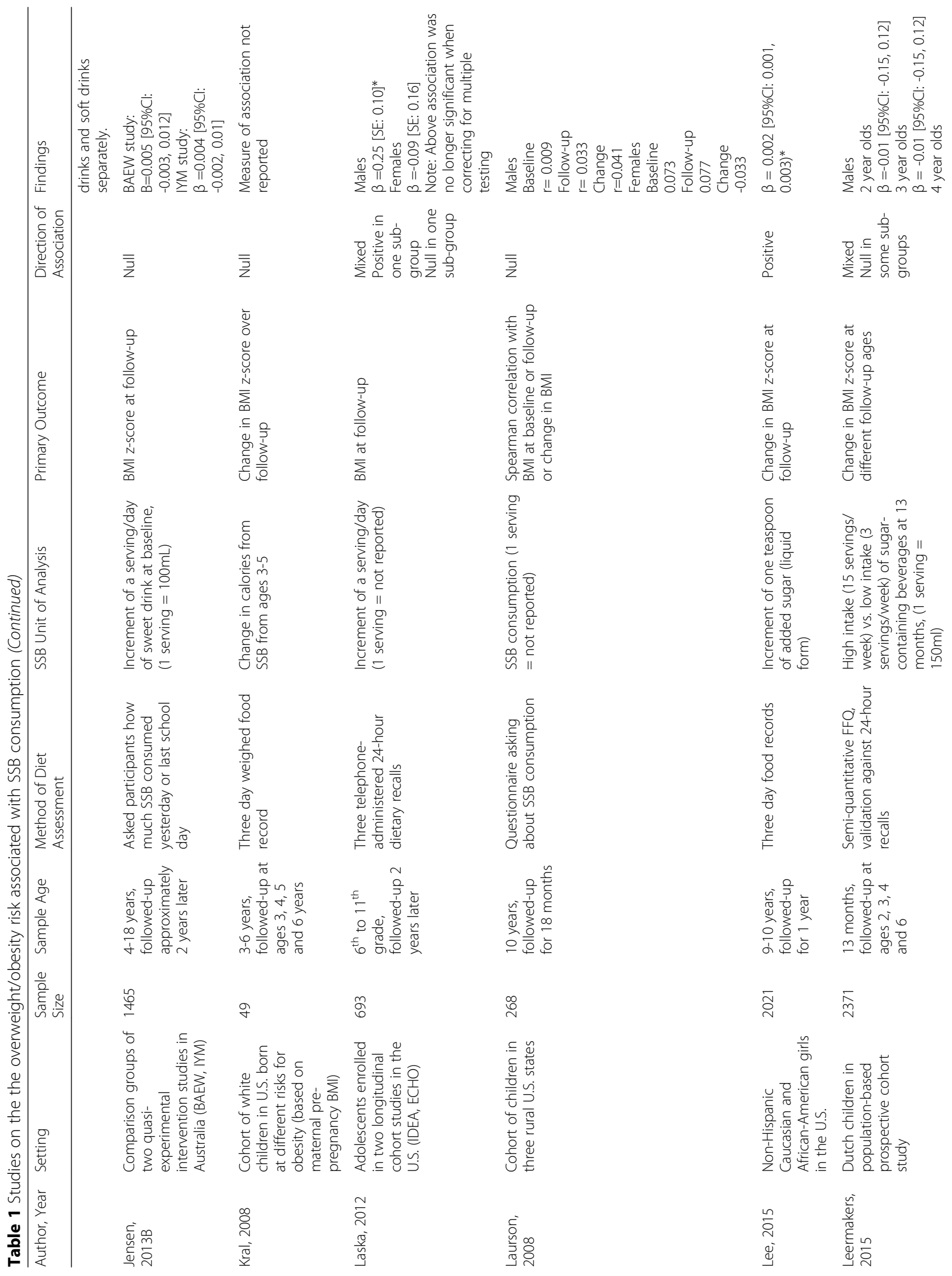









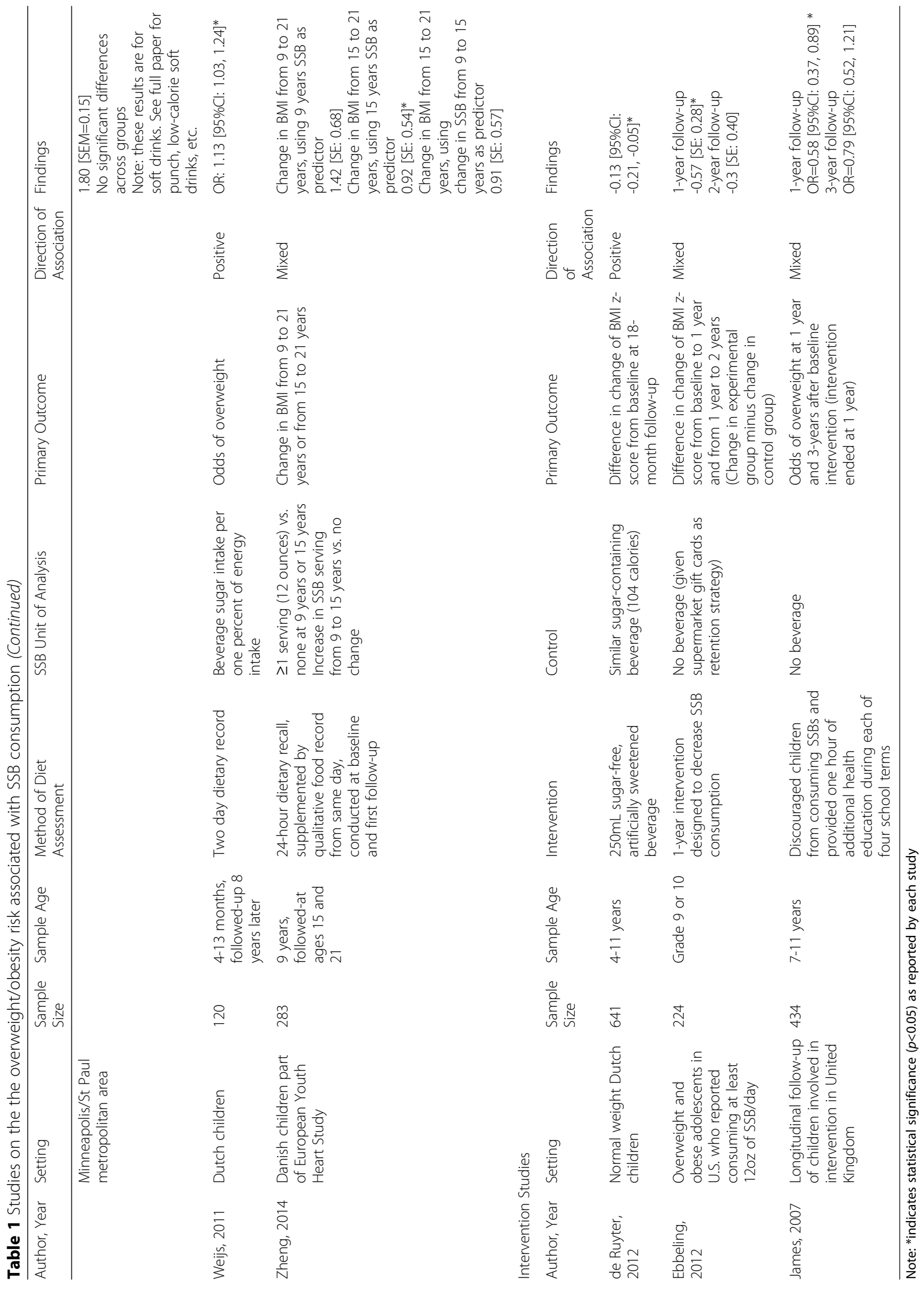


SSB serving (serving $=8$ fluid ounces) per day at 2 years old had a significantly greater increase in BMI z-score over the next 2 years compared to infrequent/non SSB drinkers [38]. Two of the positive studies examined longitudinal associations between SSB consumption and obesity risk among minority populations, with one finding that high SSB intake (defined as greater than median intake in study population) among Latino toddlers was associated with a 0.46 unit increase in weight for height $\mathrm{z}$-score at 6-month follow-up [37] and the other finding that SSBs were positively associated with 2-year overweight risk among AfricanAmerican preschool children [47].

Some studies found mixed results [36-38, 40, 44, 45, 52], with two reporting the positive association between SSB intake and increased weight was only significant among girls $[36,45]$. The first study found high SSB intake $(\geq 15$ servings/week) at 13 months old was significantly associated with an increased BMI among girls at ages 2, 3, 4, and 6 years old [45]. Another study found that girls who moved to the top tertile of SSB consumption ( $>335 \mathrm{~g} /$ day) between 14 and 17 years of age had increased BMI and nearly a five-fold greater odds of overweight or obesity risk compared to girls who remained in the lowest tertile of SSB consumption [36]. One study found a positive association when using SSB consumption at 15 years to predict change in BMI from ages 15-21 and found null results when using SSB consumption at 9 years as a predictor [52].

Some of the longitudinal studies found no association between SSBs and BMI or BMI z-scores [41-44, 46, 50, 54, 57].

\section{Intervention studies}

A small number of intervention studies have examined SSB consumption and overweight and obesity risk among children [58-60]. Three recent randomized controlled trials found a reduction in BMI or obesity risk in the intervention group compared to the control. De Ruyter and colleagues conducted a double-blinded placebo-controlled trial wherein 641 normal weight Dutch children were randomized to receive either a $250 \mathrm{~mL}$ of an SSB or a sugar-free beverage each day for 18 months [58]. At the end of the trial, the difference in BMI z-score was significantly different between the two groups, with the SSB group increasing on average by 0.15 units (compared to 0.02 units in the sugar-free group). The second study randomized 224 overweight and obese American adolescents who regularly consumed SSBs to either participate in a program to reduce SSB consumption or receive no intervention [59]. At the end of the 1-year intervention, those in the intervention group had beneficial changes in BMI and weight compared to those who did not receive the intervention, but these differences were no longer significant when participants were followed-up for an additional year after the end of the intervention. However, in a pre-planned subgroup analysis of Hispanic participants, there were significant differences in BMI between groups at both follow-up periods. The third study was a cluster randomized trial in which schools in the United Kingdom were randomized to either an intervention discouraging consumption of SSBs or no intervention for one year [61]. A significant difference in BMI z-score and overweight/obesity risk between groups was observed at the end of the first year, supporting a positive association between SSBs and obesity risk [61]. Two years after the intervention had been discontinued, the researchers completed a follow-up assessment and reported the differences between the groups were no longer significant [60].

\section{Insulin resistance}

A modest number of studies reported a positive association between SSB consumption and insulin resistance risk among children and adolescents, with the majority conducted cross-sectionally [62-65], one conducted longitudinally [66] and no intervention studies conducted (Table 2).

\section{Cross sectional studies}

A number of cross-sectional studies found a positive association in the whole or a subset of their study population [62-65]. For example, among 12-19 year olds in NHANES, each additional SSB serving (250 g) consumed per day was associated with a $5 \%$ increase in HOMA-IR (a marker of insulin resistance which is calculated using fasting glucose and insulin levels) [55]. One study reported associations by race, with positive associations found among White and African Americans, but null associations among Mexican Americans [18]. Another study reported a stronger association between SSB consumption and higher HOMA-IR among overweight/obese participants compared to normal weight participants [64].

\section{Longitudinal studies}

Only one longitudinal study was conducted to examine this association, reporting that an additional $10 \mathrm{~g} /$ day of added sugar from liquid sources was associated with a $0.04 \mathrm{mmol} / \mathrm{L}$ higher fasting glucose, $2.3 \mathrm{pmol} / \mathrm{L}$ higher fasting insulin and a 0.01 unit increase in HOMA-IR over two year follow-up [66].

\section{Dental caries}

A growing number of studies have examined the relationship between SSB consumption and dental caries (cavities or tooth decay) among children and adolescents, with almost all evidence pointing towards a strong positive association (Table 3). While the majority of 


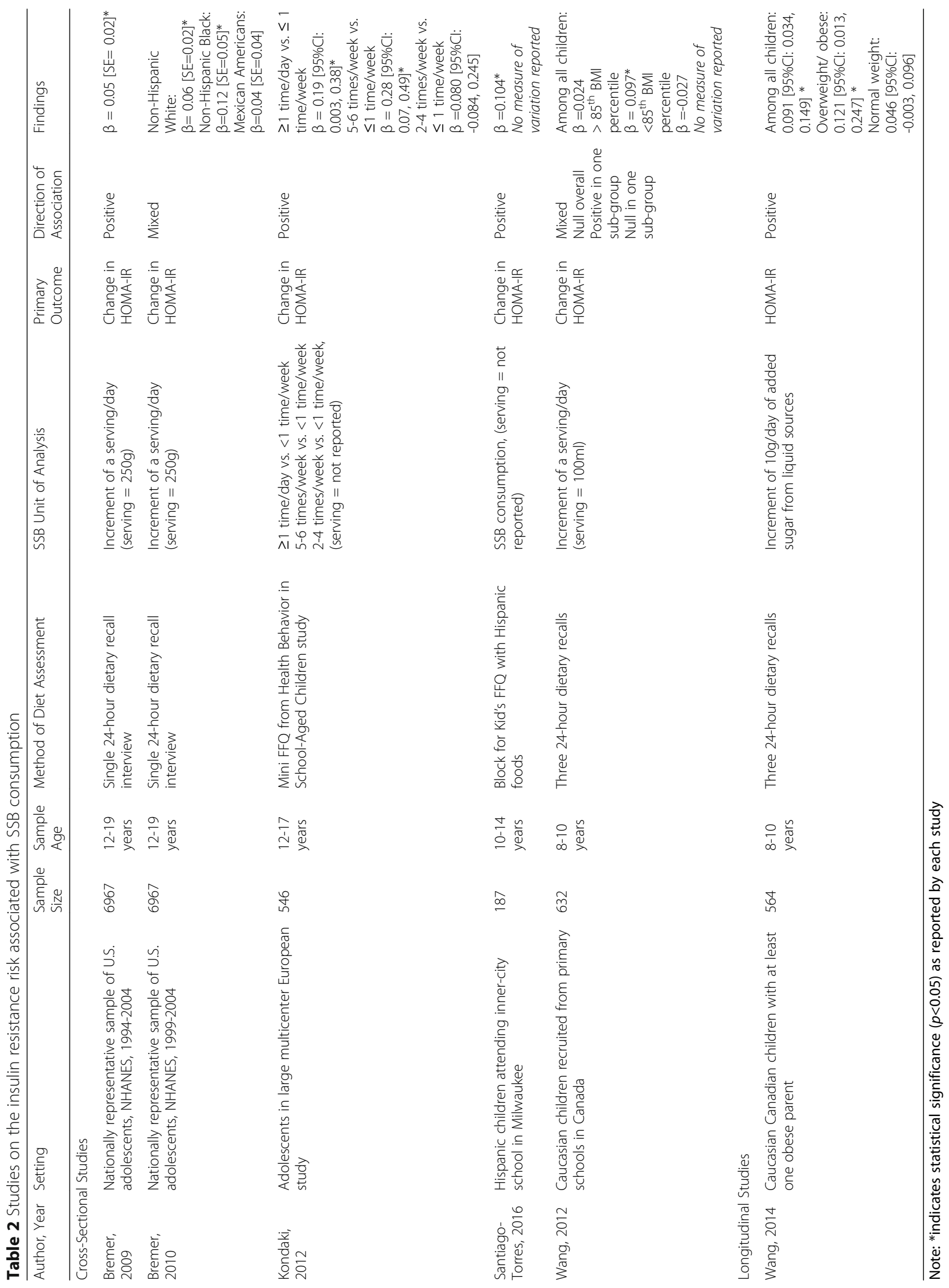




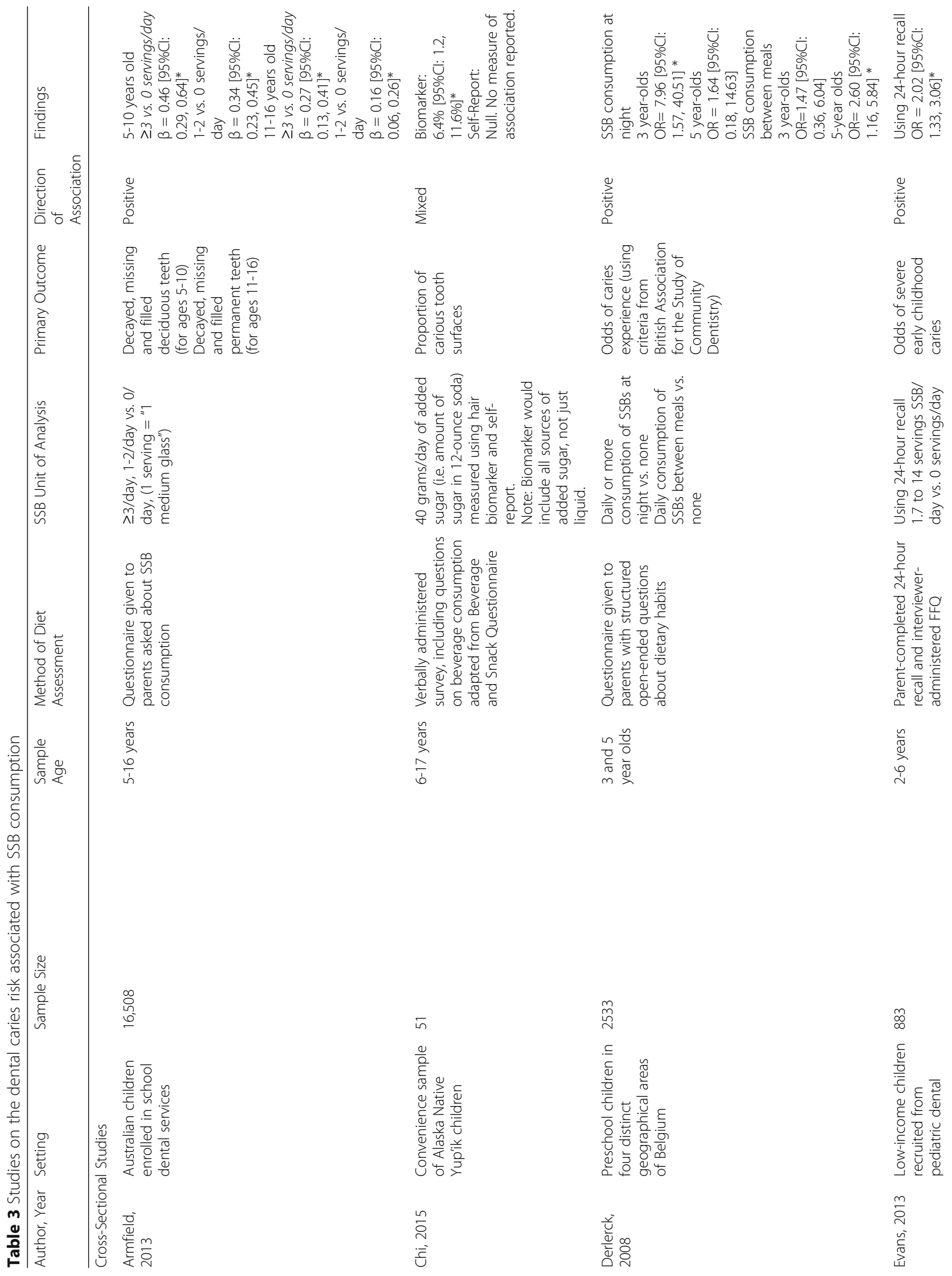




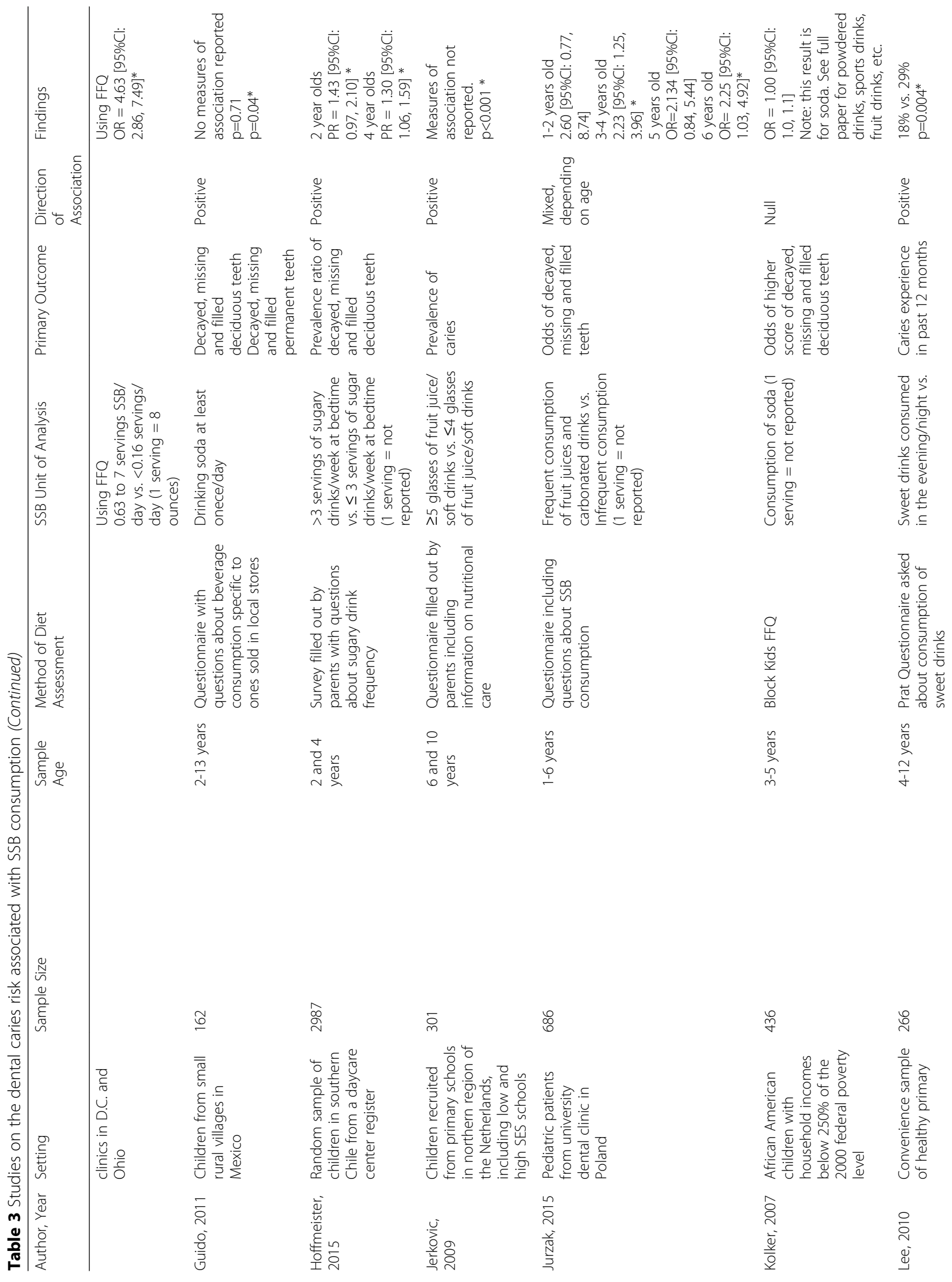














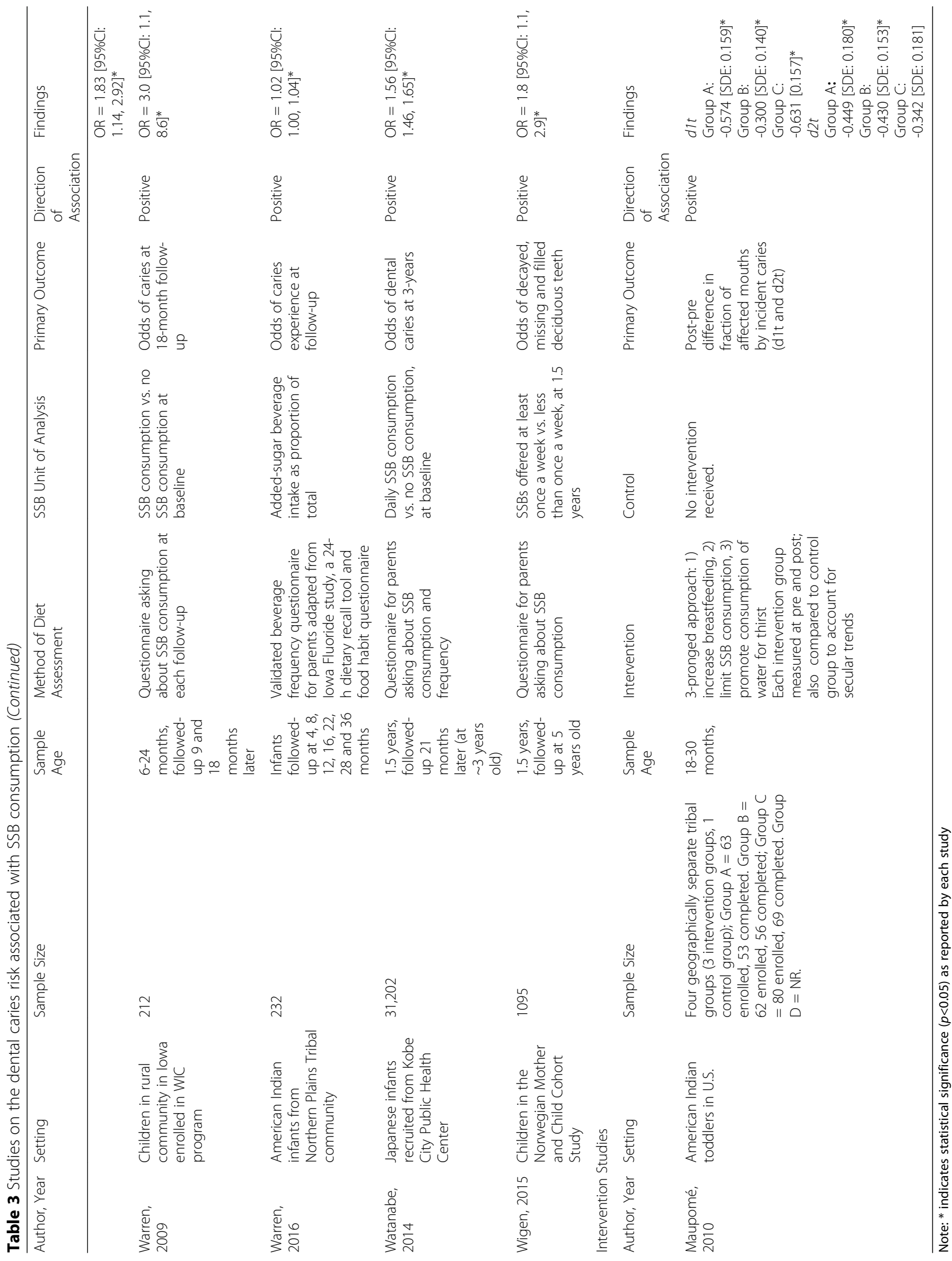


studies examining SSB intake and dental caries are cross-sectional [67-82], there have been several longitudinal studies [83-88] and one intervention study [89].

\section{Cross sectional studies}

The vast majority of cross-sectional studies found evidence for a positive association between SSB consumption and dental caries [67, 69-82]. For example, one study reported that the prevalence of caries was $22 \%$ higher for each additional SSB serving consumed by children per day [81]. Several studies replicated this positive association among low-income children [70, 73, 75], with one study reporting that high SSB consumption ( $\geq 5 \mathrm{oz} /$ day) was associated with a 4.6 greater odds of dental caries compared to those with lower SSB consumption [70]. Some studies examined how specific timing of SSB consumption affects dental caries, with one study [72] finding an association with dental caries and SSBs consumed at bedtime and another [69] finding an association with dental caries and SSBs consumed at nighttime among 3 year-olds and for SSBs consumed between meals among 5 -year olds.

One cross-sectional study reported null results, finding no association between self-reported SSB consumption and dental caries among Alaska Natives - a result which may have been related to the small sample size $(N=51)$ [68].

\section{Longitudinal studies}

All longitudinal studies included in this review found a positive or mixed association between SSB consumption and dental caries in at least part of the study population [83-88]. One study reported that a high consumption of SSBs ( $\geq 3$ servings per week) among infants 10 to 12 months old was associated with a 1.83 greater odds of dental caries at age 6, compared with infants who did not consume SSBs during infancy [84]. Some studies reported these positive findings among specific subgroups including: low-income [86], African American [83] and American Indian children [85]. For example, Lim et al. conducted a cluster analysis and reported that African American children who changed from being low consumers of SSBs at baseline (mean consumption= $567.4 \mathrm{~mL} /$ day) to high consumers of SSBs at 2-year follow-up (mean consumption $=1032.4 \mathrm{~mL} /$ day) had a 1.75 times higher mean number of new dental caries compared with high consumers of milk-juice at both baseline and 2-year follow-up [83].

\section{Intervention studies}

Only one intervention study has been conducted to assess SSB consumption and dental caries [89]. Maupomé et al. conducted community-wide interventions to reduce SSB consumption, improve breastfeeding practices, and promote consumption of water for thirst among American Indian toddlers. While the intervention communities demonstrated improvements in the number of dental caries, it is not possible to attribute this specifically to reduction in SSB consumption as the intervention was a multi-pronged approach.

\section{Caffeine-related effects}

A growing number of studies reported on the caffeine-related effects associated with SSB consumption with studies almost exclusively cross-sectional (Table 4).

\section{Cross sectional studies}

A number of cross-sectional studies examined the effects of energy drink consumption among children and adolescents [90-97], with each study often reporting on multiple outcomes. Some studies found evidence for an association between energy drink consumption and sleep-related issues such as sleep dissatisfaction, tiredness/fatigue and late bedtime [92, 93, 95], and others reported an association between energy drink intake and increased headaches [91-93]. One study reported an association between energy drink consumption and risktaking behaviors such as cigarette, marijuana and drug use [90], and two studies found an association between energy drink consumption and stress, depressive symptoms, and suicidal ideation, plan or attempt [90, 95]. Other outcomes examined in these cross-sectional studies reported include irritation [92], stomach ache and low appetite [93].

Some of the cross-sectional studies examined caffeinerelated effects of cola drinks $[93,96,97]$. One found that both low and high consumption of cola were associated with lower stress and found null associations with anxiety and depression [96]. Another examined both cola and energy drinks and found that higher consumption of both beverages was associated with headaches, stomach-aches, sleeping problems and low appetite [93]. More specifically, among males, drinking more than one cola per day was associated with a 1.34 greater odds of sleeping problems and among females drinking more than one cola per day was associated with a 1.55 greater odds of sleeping problems.

\section{Longitudinal studies}

One longitudinal study was conducted and it found evidence that increased energy drink consumption was associated with attention deficit/hyperactivity disorder inattention and hyperactivity at 16-month follow-up, but did not find evidence for associations with depression, panic and anxiety [94]. 


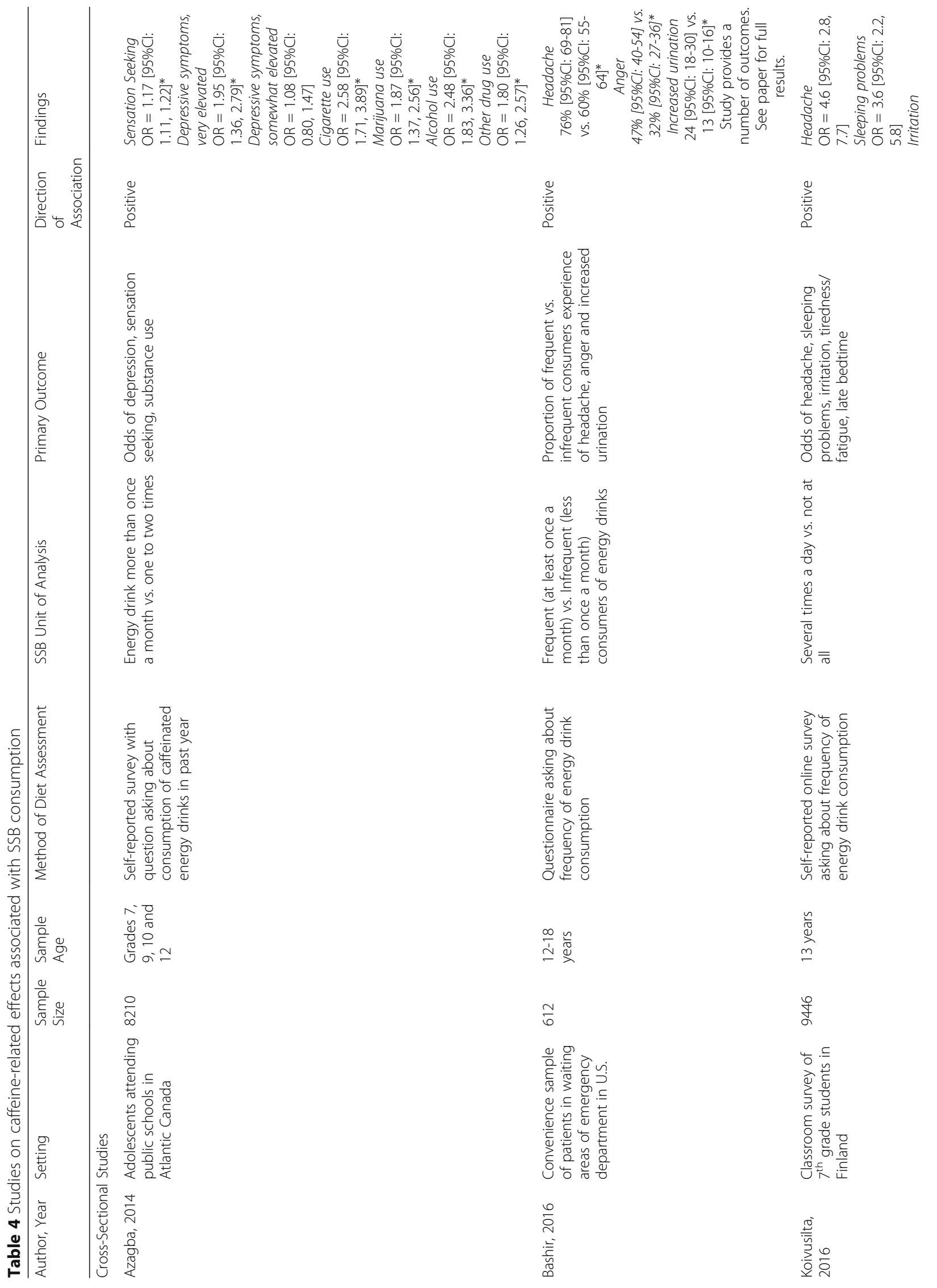




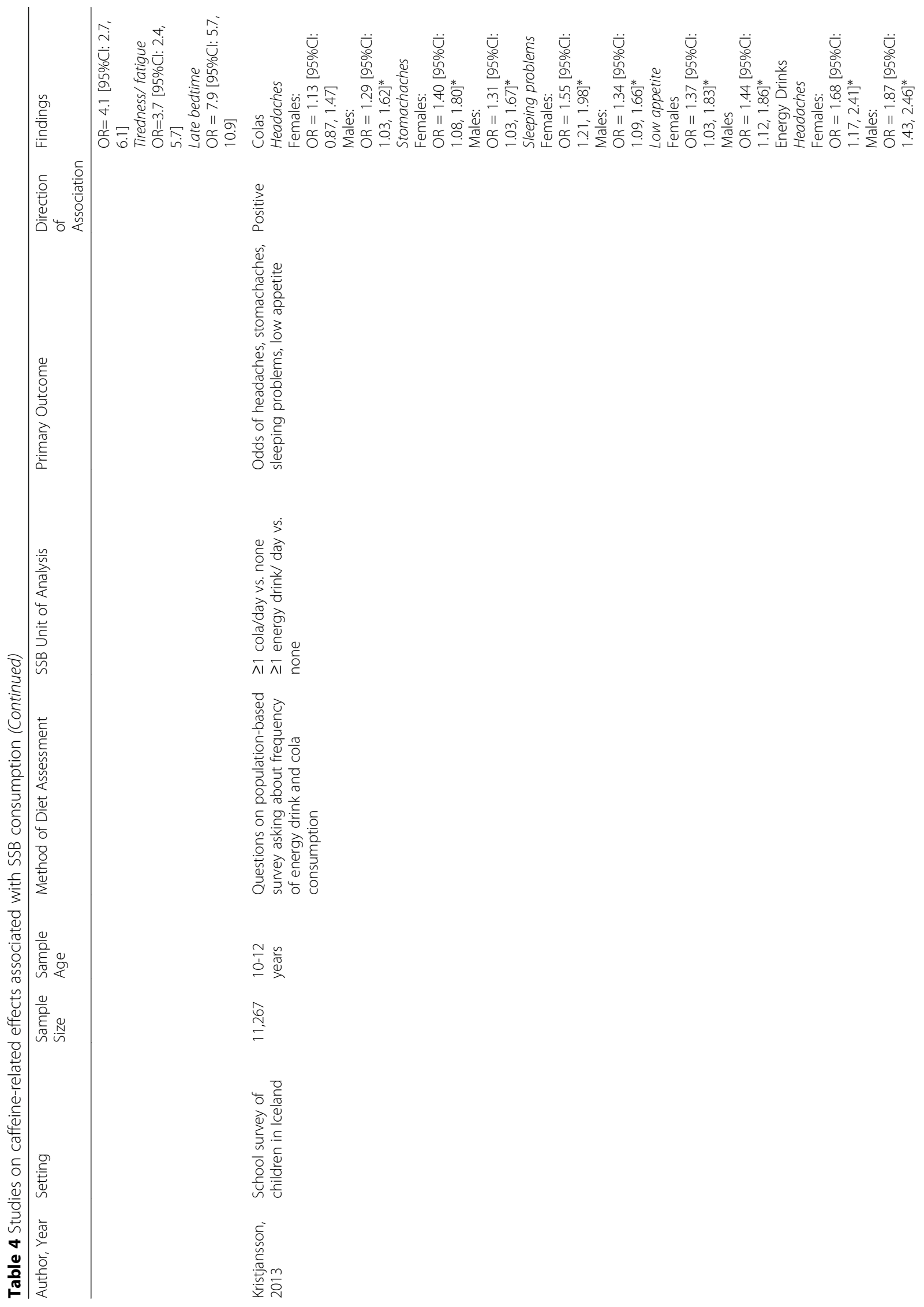




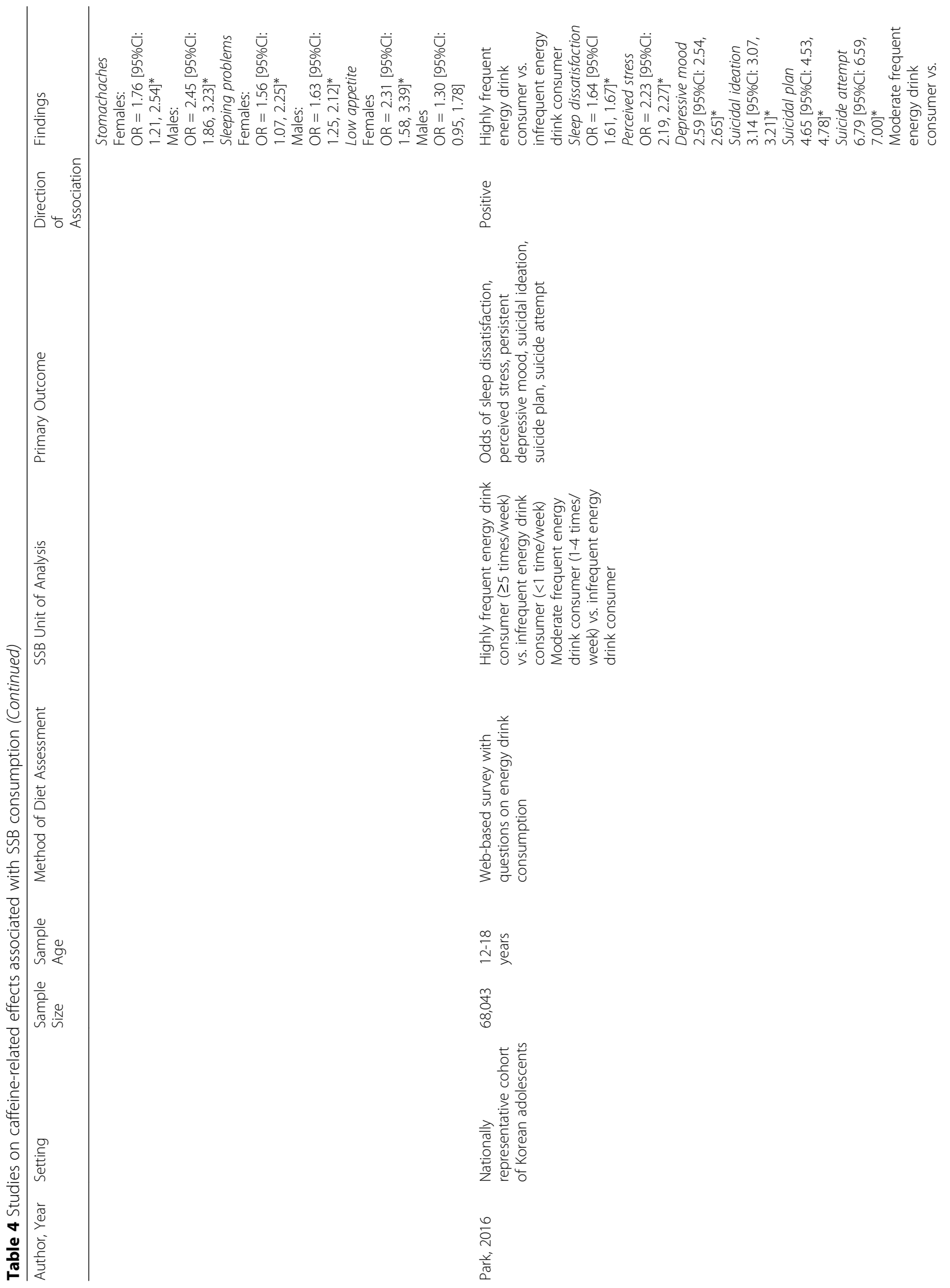




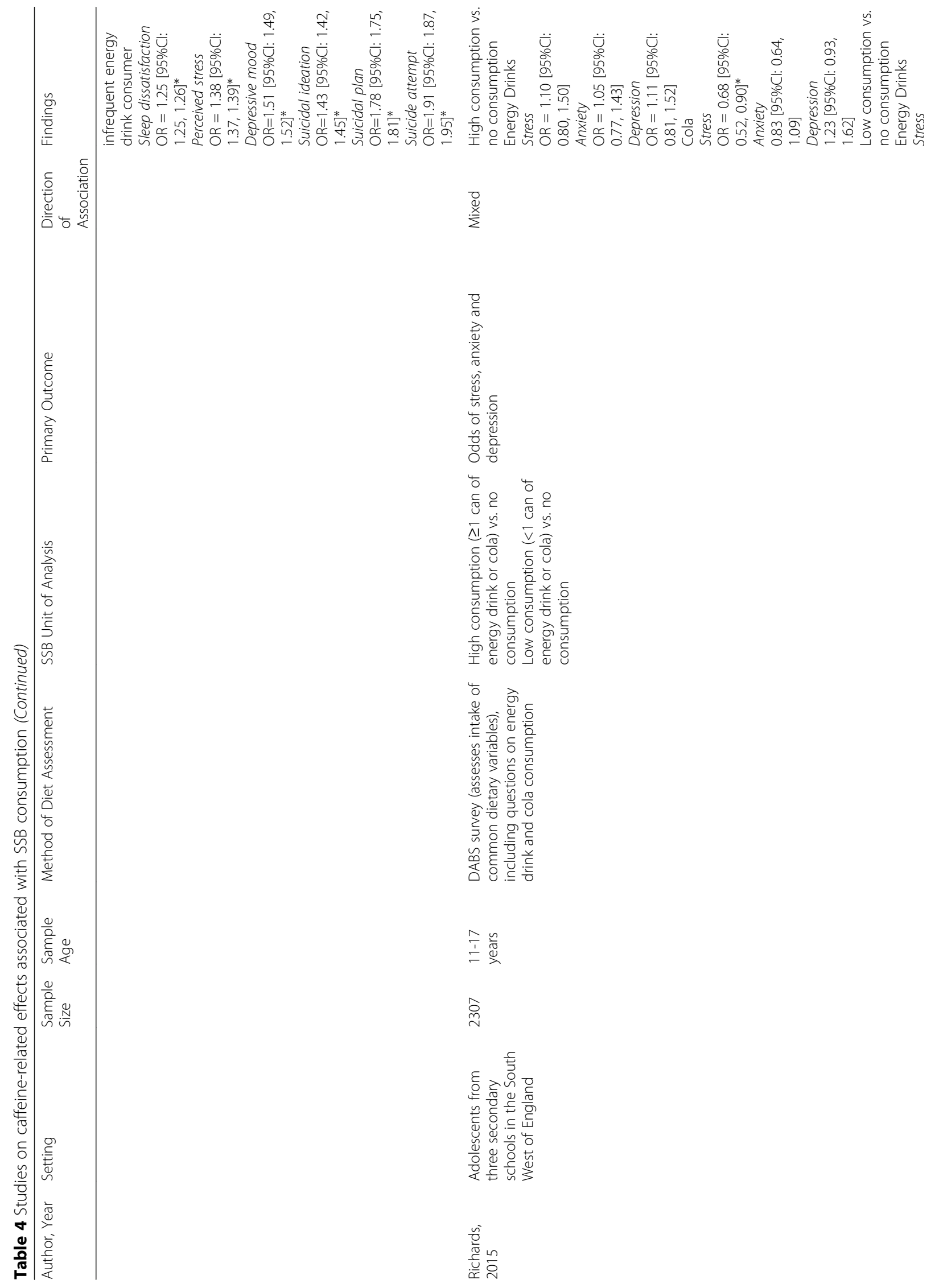




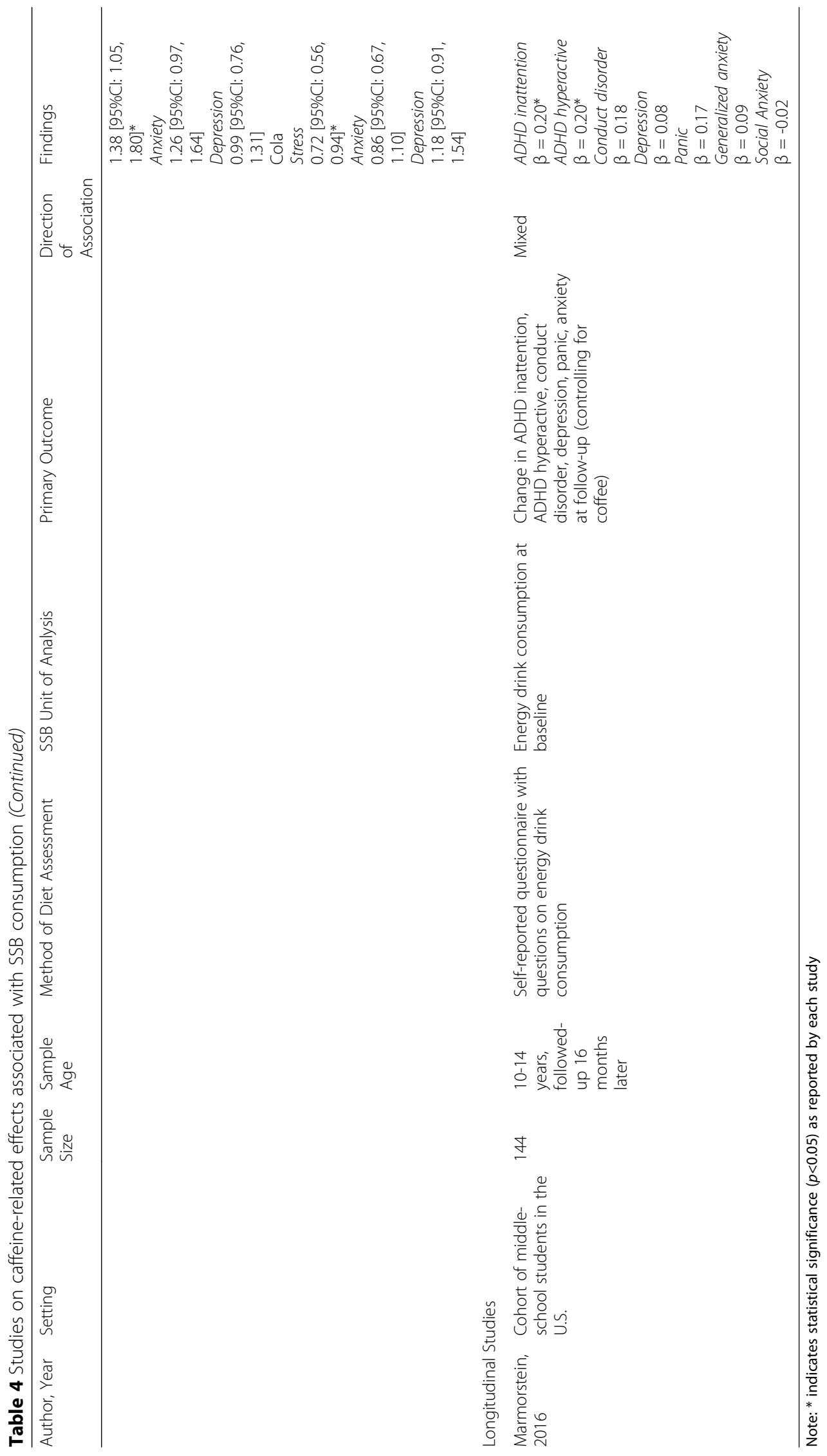




\section{Summary of evidence}

Since the most recent relevant review was published on this topic in 2009 [16], there has been a substantial increase in research examining the health consequences of SSB consumption among children and adolescents. For example, 227 studies indexed in PubMed were published on SSBs in 2017 compared to 16 studies published in 2007. ${ }^{1}$ Many more studies are now conducted exclusively on children and adolescents, while previous evidence was based on results found among adults. While the majority of this research is still cross-sectional (limiting the ability to make inferences about causality), the past decade has seen a growing number of longitudinal studies being implemented, as well as an increasing amount of intervention trials.

The majority of this research on SSBs over the past decade has centered on the relationship with weight gain. The findings of this review confirm that there is clear and consistent evidence that the consumption of SSBs heightens obesity risk among children and adolescents. Although a formal quality assessment or strength of evidence evaluation was not conducted, the vast majority of cross-sectional, longitudinal and intervention studies find strong evidence for a positive relationship in all or part of their study population. The exact mechanism through which SSBs impact childhood obesity is not entirely understood. Generally, the research points to the low satiety of SSBs and incomplete compensation $[98,99]$. In other words, drinking calories in liquid form does not decrease hunger in the same way as solid food. Additionally, people do not sufficiently reduce their total energy intake to make up for the excess calories obtained from SSBs. There is also a lively debate about whether the effect of calories from SSBs on body weight is worse than some other foods or nutrients [100, 101].

The association between SSB consumption and weight gain is paramount, given that childhood obesity affects roughly one in six (13 million) children in the U.S., disproportionately impacting children who are low-income and racial and ethnic minorities [102]. From 1976 to 2016, the prevalence of childhood obesity in the U.S. more than doubled in children ages 2 to 5 (from 5\% to $13.9 \%$ ), nearly tripled in children aged 6 to 11 (from $6.5 \%$ to $18.4 \%$ ) and quadrupled in adolescents' ages 12 to 19 (from $5 \%$ to $20.6 \%$ ) [103-105]. While there is some indication that childhood obesity rates may leveling in the U.S. [104], the overall prevalence of obesity among children in 2016-2016 was estimated at 18.5\% [105], meaning it is still considerably higher than the Healthy People 2020 goal of $14.5 \%$ [4]. Given that children who are overweight and obese youth are likely to remain so as adults [106], obesity and its adverse health consequences create a serious threat to children's current and future health [107]. Hence, reducing SSB consumption is an important intervention point to reduce the burden of childhood obesity in the U.S.

This review also finds strong and consistent evidence that consumption of SSBs is associated with dental caries among children and adolescents. The mechanism for the association between SSB consumption and dental caries is well understood: dental caries are caused by acids produced by bacteria metabolizing sugar in the mouth. Increased sugar from SSBs intensifies the acid production and causes further decay of teeth [108]. The majority of studies examining this relationship are cross-sectional, but a modest number of longitudinal studies as well as one intervention study also support the association.

While evidence has shown a positive relationship between SSB consumption and type 2 diabetes among adults [5, 12, 109], the available literature among child and adolescents is limited. The majority of studies among children and adolescents do not directly examine the link between SSB consumption and type 2 diabetes and instead measure insulin resistance, a biomarker of increased cardio-metabolic risk and type 2 diabetes. It is hypothesized that the high content of sucrose and highfructose corn syrup present in SSBs may increase dietary glycemic load leading to insulin resistance and inflammation [7]. While not as strong and consistent as the relationships between SSB consumption and weight gain or dental caries, most studies in this review generally support an association between SSB consumption and insulin resistance among children and adolescents. However, this is limited by a small number of studies and the predominance of a cross-sectional study design.

The findings of this review also point to an association between caffeinated SSBs and a wide range of health issues including poor quality or reduced sleep, headaches, risk-seeking behavior and depressive symptoms. The presence of caffeine in energy drinks and other caffeinated SSBs (e.g., cola), in conjunction with the large volumes consumed, can lead to neurological and psychological effects associated with high caffeine consumption. The majority of studies examining the caffeine-related effects of SSBs focus on energy drinks, with very few analyzing the effects of other caffeinated SSBs such as colas. One reason for this may be the considerably higher level of caffeine content in energy drinks: a $250 \mathrm{~mL}$ energy drink has an average of $80 \mathrm{mg}$ of caffeine (range: $27-87 \mathrm{mg}$ ), compared to $40 \mathrm{~g}$ of caffeine (range: $30-60 \mathrm{mg}$ ) in a $330 \mathrm{~mL}$ cola drink [110]. Additionally, studies examining caffeinerelated effects have almost exclusively been crosssectional, limiting the strength of inferences that can be made and bringing forth issues of reverse causation.

While there is a large and growing body of research examining the impact of SSBs on children's health, 
important gaps remain. First, researchers should utilize more rigorous study designs (intervention trials and longitudinal studies) and move away from a reliance on cross-sectional studies. This will strengthen the evidence base and allow firmer conclusions to be made regarding the causal relationships between SSB consumption and negative health consequences. Second, more consistency is needed in the definition of SSBs (e.g., specifying which beverages are included and what is a typical serving size) and measurement strategy (e.g., FFQ vs. 24-h recall). Similarly, more uniformity is needed in assessing outcomes, particularly in the risk of overweight/obesity where studies vary considerably in the outcomes measured (e.g., BMI, BMI z-score, BMI percentile, overweight/obese status). Third, researchers should more rigorously examine differences in health risks by subpopulations (e.g., race/ethnicity, socioeconomic status, age and gender) to determine if the intake of SSBs in particularly harmful in certain population subsets. While it is established that lowincome and racial and ethnic minorities consume more SSBs, it is unclear the extent to which health consequences are magnified among these groups. This is important particularly for targeting interventions and policy approaches to reduce children's SSB consumption. Better insights in these areas have the potential to inform realworld policies and recommendations that may greatly benefit children's health. Finally, additional research is needed about caffeinated SSBs and their impact on children's health. Energy and sport drink consumption is rising rapidly in the U.S. [13] and so studies examining the negative health effects of caffeinated SSBs are needed to inform future efforts to reduce consumption.

This review has several limitations. First, it only focuses on four main health effects associated with SSB consumption and does not address other potential consequences which have been documented among consumers of SSBs (e.g., hyperlipidemia, non-alcoholic fatty liver disease). Second, our conclusions for a particular health consequence did not include a quality assessment and was limited to an informal evaluation of consistency and lack of conflicting studies. Third, article screening was not done in duplicate, although all included articles were confirmed by a second reviewer.

\section{Conclusion}

This review provides clear and consistent evidence that consumption of SSBs increases obesity risk and dental caries among children and adolescents, with emerging evidence supporting an association with insulin resistance and caffeine-related effects. In general, the strength of evidence for all four health consequences could be improved through the implementation of more longitudinal and intervention studies. Additionally, more consistency is needed from studies in the measurement of exposures (e.g., standardized measurement and definition of SSBs) and outcomes (e.g., assessment of weight-related outcomes) to create a stronger evidence base. Future research should compare low-income and racial/ethnic minority subgroups in order to determine if differences in health risks associated with SSBs exist. Although SSB consumption has declined in the last 15 years, consumption still remains high (61\% of children consume at least one SSB per day). The vast majority of the available literature suggests that reducing SSB consumption would improve children's health.

\section{Endnotes \\ ${ }^{1}$ Author calculations, based on PubMed results by year.}

\section{Additional file}

Additional file 1: Appendix. Search Strategies (Contains the full list of search terms and PRISMA diagrams). (DOCX 128 kb)

\section{Abbreviations}

BMI: Body mass index; NHANES: National Health and Nutritional Examination Survey; OECD: Organisation for Economic Co-operation and Development;

SSB: Sugar-sweetened beverage

\section{Acknowledgements \\ Not applicable \\ Funding \\ This work was funded by the Robert Wood Johnson Foundation Healthy Eating Research Program.}

Availability of data and materials

Please contact author for data requests.

Authors' contributions

SNB designed the research. KAV conducted the review. SNB and KAV drafted and revised the paper for intellectual content. SNB had primary responsibility for final content. Both authors read and approved the final manuscript.

Ethics approval and consent to participate

Not applicable

Consent for publication

Not applicable

Competing interests

The authors declare that they have no competing interests.

\section{Publisher's Note}

Springer Nature remains neutral with regard to jurisdictional claims in published maps and institutional affiliations.

\section{Author details}

${ }^{1}$ Department of Health Policy and Management, Harvard T.H. Chan School of Public Health, Boston, MA, USA. ${ }^{2}$ Department of Epidemiology, Harvard T.H. Chan School of Public Health, Boston, USA. 
Received: 30 May 2017 Accepted: 26 December 2017 Published online: 20 February 2018

\section{References}

1. US Department of Health and Human Services USDoA. 2015-2020 Dietary guidelines for Americans. 8th ed.. Washington (DC): USDA. 2015.

2. Bleich SN, Wolfson JA. Trends in SSBs and snack consumption among children by age, body weight, and race/ethnicity. Obesity. 2015;23(5):1039-46.

3. Bleich SN, Vercammen KA, Kom JW, Zhonghe L. Trends in beverage consumption among children and adults, 2003-2014. Obesity. 2017;

4. Malik VS, Pan A, Willett WC, Hu FB. Sugar-sweetened beverages and weight gain in children and adults: a systematic review and meta-analysis. Am J Clin Nutr. 2013;98(4):1084-102.

5. Resolved HFB. There is sufficient scientific evidence that decreasing sugarsweetened beverage consumption will reduce the prevalence of obesity and obesity-related diseases. Obesity reviews : an official journal of the International Association for the Study of Obesity. 2013;14(8):606-19. https://doi.org/10.1111/obr.12040.

6. Malik VS, Popkin BM, Bray GA, Després J-P, Hu FB. Sugar-sweetened beverages, obesity, type 2 diabetes mellitus, and cardiovascular disease risk. Circulation. 2010;121(11):1356-64

7. Malik VS, Popkin BM, Bray GA, Després J-P, Willett WC, Hu FB. Sugarsweetened beverages and risk of metabolic syndrome and type 2 diabetes. Diabetes Care. 2010;33(11):2477-83.

8. Schulze MB, Manson JE, Ludwig DS, Colditz GA, Stampfer MJ, Willett WC, et al. Sugar-sweetened beverages, weight gain, and incidence of type 2 diabetes in young and middle-aged women. JAMA. 2004;292(8):927-34.

9. Nseir W, Nassar F, Assy N. Soft drinks consumption and nonalcoholic fatty liver disease. World J Gastroenterol: WJG. 2010;16(21):2579.

10. Tahmassebi J, Duggal M, Malik-Kotru G, Curzon M. Soft drinks and dental health: a review of the current literature. J Dent. 2006:34(1):2-11.

11. Davis JN, Ventura EE, Weigensberg MJ, Ball GD, Cruz ML, Shaibi GQ, et al. The relation of sugar intake to $\beta$ cell function in overweight Latino children. Am J Clin Nutr. 2005;82(5):1004-10.

12. Hu FB, Malik VS. Sugar-sweetened beverages and risk of obesity and type 2 diabetes: epidemiologic evidence. Physiol Behav. 2010;100(1):47-54. https://doi.org/10.1016/j.physbeh.2010.01.036.

13. Al-Shaar L, Vercammen K, Lu C, Richardson S, Tamez M, Mattei J. Health effects and public health concerns of energy drink consumption in the United States: a mini-review. Front Public Health. 2017:5:225.

14. Forshee RA, Anderson PA, Storey ML. Sugar-sweetened beverages and body mass index in children and adolescents: a meta-analysis. Am J Clin Nutr. 2008;87(6):1662-71.

15. Harrington S. The role of sugar-sweetened beverage consumption in adolescent obesity: a review of the literature. J Sch Nurs. 2008;24(1):3-12.

16. Gortmaker $S$, Long M, Wang YC. The negative impact of sugar-sweetened beverages on Children's health: a research synthesis. Robert Wood Johnson Foundation; 2009.

17. Beck AL, Tschann J, Butte NF, Penilla C, Greenspan LC. Association of beverage consumption with obesity in Mexican American children. Public Health Nutr. 2014;17(2):338-44. https://doi.org/10.1017/s1368980012005514.

18. Bremer AA, Byrd RS, Auinger P. Differences in male and female adolescents from various racial groups in the relationship between insulin resistanceassociated parameters with sugar-sweetened beverage intake and physical activity levels. Clin Pediatr. 2010;49(12):1134-42. https://doi.org/10.1177/ 0009922810379043.

19. Clifton PM, Chan L, Moss CL, Miller MD, Cobiac L. Beverage intake and obesity in Australian children. Nutrition \& metabolism. 2011:8:87. https://doi.org/10.1186/1743-7075-8-87.

20. Coppinger $T$, Jeanes $Y$, Mitchell $M$, Reeves $S$. Beverage consumption and BMI of British schoolchildren aged 9-13 years. Public Health Nutr. 2013;16(7): 1244-9. https://doi.org/10.1017/s1368980011002795.

21. Danyliw AD, Vatanparast H, Nikpartow N, Whiting SJ. Beverage patterns among Canadian children and relationship to overweight and obesity. Applied physiology, nutrition, and metabolism = Physiologie appliquee, nutrition et metabolisme. 2012;37(5):900-6. https://doi.org/10.1139/h2012-074.

22. Davis JN, Koleilat M, Shearrer GE, Whaley SE. Association of infant feeding and dietary intake on obesity prevalence in low-income toddlers. Obesity (Silver Spring, Md). 2014;22(4):1103-11. https://doi.org/10.1002/oby.20644.
23. Davis JN, Whaley SE, Goran MI. Effects of breastfeeding and low sugarsweetened beverage intake on obesity prevalence in Hispanic toddlers. Am J Clin Nutr. 2012;95(1):3-8. https://doi.org/10.3945/ajcn.111.019372.

24. Denova-Gutierrez E, Jimenez-Aguilar A, Halley-Castillo E, Huitron-Bravo G, Talavera JO, Pineda-Perez D, et al. Association between sweetened beverage consumption and body mass index, proportion of body fat and body fat distribution in Mexican adolescents. Annals of nutrition \& metabolism. 2008;53(3-4):245-51. https://doi.org/10.1159/000189127.

25. Gibson S, Neate D. Sugar intake, soft drink consumption and body weight among British children: further analysis of National Diet and nutrition survey data with adjustment for under-reporting and physical activity. Int J Food Sci Nutr. 2007;58(6):445-60. https://doi.org/10.1080/096374880701288363.

26. Gómez-Martínez S, Martín A, Romeo Marín J, Castillo Garzón MJ, Mesena M, Baraza J et al. Is soft drink consumption associated with body composition? A cross-sectional study in Spanish adolescents. 2009.

27. Grimes CA, Riddell LJ, Campbell KJ, Nowson CA. Dietary salt intake, sugarsweetened beverage consumption, and obesity risk. Pediatrics. 2013;131(1): 14-21. https://doi.org/10.1542/peds.2012-1628.

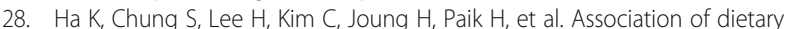
sugars and sugar-sweetened beverage intake with obesity in Korean children and adolescents. Nutrients. 2016:8(1):31.

29. Kosova EC, Auinger P, Bremer AA. The relationships between sugar-sweetened beverage intake and cardiometabolic markers in young children. J Acad Nutr Diet. 2013;113(2):219-27. https://doi.org/10.1016/j.jand.2012.10.020.

30. Linardakis M, Sarri K, Pateraki MS, Sbokos M, Kafatos A. Sugar-added beverages consumption among kindergarten children of Crete: effects on nutritional status and risk of obesity. BMC Public Health. 2008;8:279. https://doi.org/10.1186/1471-2458-8-279.

31. Papandreou D, Andreou E, Heraclides A, Rousso II. Beverage intake related to overweight and obesity in school children? Hippokratia. 2013;17(1):42-6.

32. Schroder H, Mendez MA, Ribas L, Funtikova AN, Gomez SF, Fito M, et al. Caloric beverage drinking patterns are differentially associated with diet quality and adiposity among Spanish girls and boys. Eur J Pediatr. 2014; 173(9):1169-77. https://doi.org/10.1007/s00431-014-2302-X.

33. Valente $H$, Teixeira V, Padrao P, Bessa M, Cordeiro T, Moreira A, et al. Sugarsweetened beverage intake and overweight in children from a Mediterranean country. Public Health Nutr. 2011;14(1):127-32. https://doi.org/10.1017/ s1368980010002533.

34. Bremer AA, Auinger $P$, Byrd RS. Sugar-sweetened beverage intake trends in US adolescents and their association with insulin resistance-related parameters. Journal of nutrition and metabolism. 2010;2010 https://doi.org/10.1155/2010/ 196476.

35. Jiménez-Aguilar A, Flores M, Shamah-Levy T. Sugar-sweetened beverages consumption and BMI in Mexican adolescents: Mexican National Health and nutrition survey 2006. Salud Publica Mex. 2009;51:S604-S12.

36. Ambrosini GL, Oddy WH, Huang RC, Mori TA, Beilin $\sqcup$, Jebb SA. Prospective associations between sugar-sweetened beverage intakes and cardiometabolic risk factors in adolescents. Am J Clin Nutr. 2013;98(2):327-34. https://doi.org/10. 3945/ajen.112.051383.

37. Chaidez V, McNiven S, Vosti SA, Kaiser LL. Sweetened food purchases and indulgent feeding are associated with increased toddler anthropometry. J Nutr Educ Behav. 2014;46(4):293-8. https://doi.org/10.1016/j.jneb.2013.05.011.

38. DeBoer MD, Scharf RJ, Demmer RT. Sugar-sweetened beverages and weight gain in 2- to 5-year-old children. Pediatrics. 2013;132(3):413-20. https://doi. org/10.1542/peds.2013-0570.

39. Dubois L, Farmer A, Girard M, Peterson K. Regular sugar-sweetened beverage consumption between meals increases risk of overweight among preschool-aged children. J Am Diet Assoc. 2007;107(6):924-934; discussion 34-5. https://doi.org/10.1016/j.jada.2007.03.004.

40. Field AE, Sonneville KR, Falbe J, Flint A, Haines J, Rosner B, et al. Association of sports drinks with weight gain among adolescents and young adults. Obesity (Silver Spring, Md). 2014;22(10):2238-43. https://doi.org/10.1002/oby. 20845.

41. Jensen BW, Nichols M, Allender S, de Silva-Sanigorski A, Millar L, Kremer P, et al. Inconsistent associations between sweet drink intake and 2-year change in BMI among Victorian children and adolescents. Pediatric obesity. 2013;8(4):271-83. https://doi.org/10.1111/j.2047-6310.2013.00174.x.

42. Jensen BW, Nielsen BM, Husby I, Bugge A, El-Naaman B, Andersen LB, et al. Association between sweet drink intake and adiposity in Danish children participating in a long-term intervention study. Pediatric obesity. 2013;8(4): 259-70. https://doi.org/10.1111/j.2047-6310.2013.00170.x. 
43. Kral TVE, Stunkard AJ, Berkowitz RI, Stallings VA, Moore RH, Faith MS. Beverage consumption patterns of children born at different risk of obesity. Obesity. 2008;16(8):1802-8. https://doi.org/10.1038/oby.2008.287.

44. Laska MN, Murray DM, Lytle LA, Harnack LJ. Longitudinal associations between key dietary behaviors and weight gain over time: transitions through the adolescent years. Obesity (Silver Spring, Md). 2012;20(1):118-25. https://doi.org/10.1038/oby.2011.179.

45. Leermakers ET, Felix JF, Erler NS, Cerimagic A, Wijtzes Al, Hofman A, et al. Sugar-containing beverage intake in toddlers and body composition up to age 6 years: the generation R study. Eur J Clin Nutr. 2015;69(3):314-21. https://doi.org/10.1038/ejen.2015.2.

46. Libuda L, Alexy U, Sichert-Hellert W, Stehle P, Karaolis-Danckert N, Buyken $A E$, et al. Pattern of beverage consumption and long-term association with body-weight status in German adolescents-results from the DONALD study. Br J Nutr. 2008;99(6):1370-9. https://doi.org/10.1017/s0007114507862362.

47. Lim S, Zoellner JM, Lee JM, Burt BA, Sandretto AM, Sohn W, et al. Obesity and sugar-sweetened beverages in African-American preschool children: a longitudinal study. Obesity (Silver Spring, Md). 2009;17(6):1262-8. https://doi. org/10.1038/oby.2008.656.

48. Millar L, Rowland B, Nichols M, Swinburn B, Bennett C, Skouteris H, et al. Relationship between raised $\mathrm{BMI}$ and sugar sweetened beverage and high fat food consumption among children. Obesity (Silver Spring, Md). 2014; 22(5):E96-103. https://doi.org/10.1002/oby.20665.

49. Pan L, Li R, Park S, Galuska DA, Sherry B, Freedman DS. A longitudinal analysis of sugar-sweetened beverage intake in infancy and obesity at 6 years. Pediatrics. 2014;134(Suppl 1):S29-35. https://doi.org/10.1542/peds. 2014-0646F.

50. Vanselow MS, Pereira MA, Neumark-Sztainer D, Raatz SK. Adolescent beverage habits and changes in weight over time: findings from project EAT. Am J Clin Nutr. 2009;90(6):1489-95. https://doi.org/10.3945/ajcn.2009.27573.

51. Weijs PJ, Kool LM, van Baar NM, van der Zee SC. High beverage sugar as well as high animal protein intake at infancy may increase overweight risk at 8 years: a prospective longitudinal pilot study. Nutr J. 2011;10:95. https://doi.org/10.1186/1475-2891-10-95.

52. Zheng M, Rangan A, Olsen NJ, Andersen LB, Wedderkopp N, Kristensen P, et al. Sugar-sweetened beverages consumption in relation to changes in body fatness over 6 and 12 years among 9-year-old children: the European youth heart study. Eur J Clin Nutr. 2014;68(1):77-83. https://doi.org/10.1038/ ejcn.2013.243.

53. Fiorito LM, Marini M, Francis LA, Smiciklas-Wright H, Birch LL. Beverage intake of girls at age 5 y predicts adiposity and weight status in childhood and adolescence. Am J Clin Nutr. 2009;90(4):935-42.

54. Laurson K, Eisenmann JC, Moore S. Lack of association between television viewing, soft drinks, physical activity and body mass index in children. Acta Paediatr. 2008;97(6):795-800

55. Bremer AA, Auinger P, Byrd RS. Sugar-sweetened beverage intake trends in US adolescents and their association with insulin resistance-related parameters. Journal of nutrition and metabolism. 2009;2010

56. Lee A, Chowdhury R, Welsh J. Sugars and adiposity: the long-term effects of consuming added and naturally occurring sugars in foods and in beverages. Obesity science \& practice. 2015;1(1):41-9.

57. Stoof SP, Twisk JWR, Olthof MR. Is the intake of sugar-containing beverages during adolescence related to adult weight status? Public Health Nutr. 2013; 16(7):1257-62. https://doi.org/10.1017/s1368980011002783.

58. de Ruyter JC, Olthof MR, Seidell JC, Katan MBA. Trial of sugar-free or sugarsweetened beverages and body weight in children. N Engl J Med. 2012; 367(15):1397-406.

59. Ebbeling CB, Feldman HA, Chomitz VR, Antonelli TA, Gortmaker SL, Osganian SK, et al. A randomized trial of sugar-sweetened beverages and adolescent body weight. N Engl J Med. 2012;367(15):1407-16.

60. James J, Thomas P, Kerr D. Preventing childhood obesity: two year followup results from the Christchurch obesity prevention programme in schools (CHOPPS). BMJ. 2007;335(7623):762

61. James J, Thomas P, Cavan D, Kerr D. Preventing childhood obesity by reducing consumption of carbonated drinks: cluster randomised controlled trial. BMJ. 2004;328(7450):1237.

62. Kondaki K, Grammatikaki E, Jiménez-Pavón D, De Henauw S, Gonzalez-Gross $M$, Sjöstrom M, et al. Daily sugar-sweetened beverage consumption and insulin resistance in European adolescents: the HELENA (healthy lifestyle in Europe by nutrition in adolescence) study. Public Health Nutr. 2013;16(03): 479-86.
63. Santiago-Torres M, Cui Y, Adams AK, Allen DB, Carrel AL, Guo JY, et al. Familial and individual predictors of obesity and insulin resistance in urban Hispanic children. Pediatric obesity. 2016;11(1):54-60.

64. Wang J, Mark S, Henderson M, O'loughlin J, Tremblay A, Wortman J, et al. Adiposity and glucose intolerance exacerbate components of metabolic syndrome in children consuming sugar-sweetened beverages: QUALITY cohort study. Pediatric obesity. 2013;8(4):284-93.

65. Bremer AA, Auinger P, Byrd RS. Relationship between insulin resistanceassociated metabolic parameters and anthropometric measurements with sugar-sweetened beverage intake and physical activity levels in US adolescents: findings from the 1999-2004 National Health and nutrition examination survey. Archives of pediatrics \& adolescent medicine. 2009;163(4):328-35.

66. Wang J, Light K, Henderson M, O'loughlin J, Mathieu M-E, Paradis G, et al. Consumption of added sugars from liquid but not solid sources predicts impaired glucose homeostasis and insulin resistance among youth at risk of obesity. J Nutr. 2014;144(1):81-6.

67. Armfield JM, Spencer AJ, Roberts-Thomson KF, Plastow K. Water fluoridation and the association of sugar-sweetened beverage consumption and dental caries in Australian children. Am J Public Health. 2013;103(3):494-500.

68. Chi DL, Hopkins S, O'Brien D, Mancl L, Orr E, Lenaker D. Association between added sugar intake and dental caries in Yup'ik children using a novel hair biomarker. BMC oral health. 2015;15(1):121.

69. Declerck D, Leroy R, Martens L, Lesaffre E, Garcia-Zattera MJ, Broucke SV, et al. Factors associated with prevalence and severity of caries experience in preschool children. Community Dent Oral Epidemiol. 2008;36(2):168-78.

70. Evans EW, Hayes C, Palmer CA, Bermudez OI, Cohen SA. Must a. Dietary intake and severe early childhood caries in low-income, young children. J Acad Nutr Diet. 2013;113(8):1057-61.

71. Guido JA, EA MM, Soto A, Eggertsson H, Sanders BJ, Jones JE, et al. Caries prevalence and its association with brushing habits, water availability, and the intake of sugared beverages. Int J Paediatr Dent. 2011;21(6):432-40.

72. Hoffmeister L, Moya P, Vidal C, Benadof D. Factors associated with early childhood caries in Chile. Gac Sanit. 2016;30(1):59-62.

73. Jerkovic K, Binnekade J, Van der Kruk J, Van d, Most J, Talsma A, van der Schans C. Differences in oral health behaviour between children from high and children from low SES schools in the Netherlands. Community Dent Health. 2009;26(2):110.

74. Jurczak A, Kościelniak D, Gregorczyk-Maga I, Kołodziej I, Ciepły J, OlczakKowalczyk D, et al. Influence of socioeconomic and nutritional factors on the development of early childhood caries in children aged 1-6 years. Nowa Stomatologia. 2015;

75. Kolker JL, Yuan Y, Burt BA, Sandretto AM, Sohn W, Lang SW, et al. Dental caries and dietary patterns in low-income African American children. Pediatr Dent. 2007;29(6):457-64.

76. Lee J, Messer EPL. Intake of sweet drinks and sweet treats versus reported and observed caries experience. european archives of Paediatric Dentistry. 2010;11(1):5-17.

77. Majorana A, Cagetti MG, Bardellini E, Amadori F, Conti G, Strohmenger L, et al. Feeding and smoking habits as cumulative risk factors for early childhood caries in toddlers, after adjustment for several behavioral determinants: a retrospective study. BMC Pediatr. 2014;14(1):45.

78. Mello T, Antunes I, Waldman E, Ramos E, Relvas M, Barros H. Prevalence and severity of dental caries in schoolchildren of Porto, Portugal. Community Dent Health. 2008;25(2):119-25.

79. Pacey A, Nancarrow T, Egeland G. Prevalence and risk factors for parentalreported oral health of Inuit preschoolers: Nunavut Inuit child health survey, 2007-2008. Rural Remote Health. 2010;10(2):1368.

80. Skinner J, Byun R, Blinkhorn A, Johnson G. Sugary drink consumption and dental caries in new South Wales teenagers. Aust Dent J. 2015;60(2):169-75.

81. Wilder JR, Kaste LM, Handler A, McGruder T C, Rankin KM. The association between sugar-sweetened beverages and dental caries among third-grade students in Georgia. J Public Health Dent. 2015;

82. Nakayama $Y$, Mori M. Association between nocturnal breastfeeding and snacking habits and the risk of early childhood caries in 18-to 23-month-old Japanese children. Journal of Epidemiology. 2015;25(2):142-7.

83. Lim S, Sohn W, Burt BA, Sandretto AM, Kolker JL, Marshall TA, et al. Cariogenicity of soft drinks, milk and fruit juice in low-income african-american children: a longitudinal study. J Am Dent Assoc. 2008;139(7):959-67.

84. Park S, Lin M, Onufrak S, Li R. Association of sugar-sweetened beverage intake during infancy with dental caries in 6-year-olds. Clinical nutrition research. 2015;4(1):9-17. 
85. Warren JJ, Blanchette D, Dawson DV, Marshall TA, Phipps KR, Starr D, et al. Factors associated with dental caries in a group of American Indian children at age 36 months. Community Dent Oral Epidemiol. 2016;44(2):154-61.

86. Warren JJ, Weber-Gasparoni K, Marshall TA, Drake DR, Dehkordi-Vakil F, Dawson DV, et al. A longitudinal study of dental caries risk among very young low SES children. Community Dent Oral Epidemiol. 2009:37(2):116-22.

87. Watanabe M, Wang D-H, ljichi A, Shirai C, Zou Y, Kubo M, et al. The influence of lifestyle on the incidence of dental caries among 3-year-old Japanese children. Int J Environ Res Public Health. 2014;11(12):12611-22.

88. Wigen TI, Wang NJ. Does early establishment of favorable oral health behavior influence caries experience at age 5 years? Acta Odontol Scand. 2015;73(3):182-7.

89. Maupomé G, Karanja N, Ritenbaugh C, Lutz T, Aickin M, Becker T. Dental caries in American Indian toddlers after a community-based beverage intervention. Ethnicity \& disease. 2010;20(4):444.

90. Azagba S, Langille D, Asbridge M. An emerging adolescent health risk: caffeinated energy drink consumption patterns among high school students. Prev Med. 2014;62:54-9.

91. Bashir D, Reed-Schrader E, Olympia RP, Brady J, Rivera R, Serra T, et al. Clinical symptoms and adverse effects associated with energy drink consumption in adolescents. Pediatr Emerg Care. 2016:32(11):751-5.

92. Koivusilta L, Kuoppamäki H, Rimpelä A. Energy drink consumption, health complaints and late bedtime among young adolescents. International journal of public health. 2016;61(3):299-306.

93. Kristjansson AL, Sigfusdottir ID, Mann MJ, James JE. Caffeinated sugarsweetened beverages and common physical complaints in Icelandic children aged 10-12years. Prev Med. 2014;58:40-4.

94. Marmorstein NR. Energy drink and coffee consumption and psychopathology symptoms among early adolescents: cross-sectional and longitudinal associations. Journal of caffeine research. 2016;6(2):64-72.

95. Park S, Lee Y, Lee JH. Association between energy drink intake, sleep, stress, and suicidality in Korean adolescents: energy drink use in isolation or in combination with junk food consumption. Nutr J. 2016;15(1):87.

96. Richards G, Smith A. Caffeine consumption and self-assessed stress, anxiety, and depression in secondary school children. J Psychopharmacol. 2015: 0269881115612404.

97. Franckle RL, Falbe J, Gortmaker S, Ganter C, Taveras EM, Land T, et al. Insufficient sleep among elementary and middle school students is linked with elevated soda consumption and other unhealthy dietary behaviors. Prev Med. 2015;74:36-41.

98. DiMeglio DP, Mattes RD. Liquid versus solid carbohydrate: effects on food intake and body weight. Int J Obes. 2000;24(6):794.

99. Malik VS, Schulze MB, Intake HFB. Of sugar-sweetened beverages and weight gain: a systematic review. Am J Clin Nutr. 2006;84(2):274-88.

100. Ludwig DS. Lifespan weighed down by diet. JAMA. 2016;315(21):2269-70.

101. Slavin J. Beverages and body weight: challenges in the evidence-based review process of the carbohydrate subcommittee from the 2010 dietary guidelines advisory committee. Nutr Rev. 2012;70(suppl 2):S111-S20.

102. Wang Y. Disparities in pediatric obesity in the United States. Advances in nutrition: an international review. Journal. 2011;2(1):23-31.

103. Ogden C, Carroll M. Prevalence of obesity among children and adolescents: United States, trends 1963-1965 through 2007-2008. Centers for Disease Control and Prevention. June 2010. 2013.

104. Ogden CL, Carroll MD, Lawman HG, Fryar CD, Kruszon-Moran D, Kit BK, et al. Trends in obesity prevalence among children and adolescents in the United States, 1988-1994 through 2013-2014. JAMA. 2016;315(21):2292-9.

105. Hales C, Carroll M, Fryar C, Ogden C. Prevalence of obesity among adults and youth: United States, 2015-2016. NCHS data brief. Number 288. National Center for Health Statistics. 2017;

106. Wang LY, Chyen D, Lee S, Lowry R. The association between body mass index in adolescence and obesity in adulthood. J Adolesc Health. 2008:42(5):512-8.

107. Dietz WH. Health consequences of obesity in youth: childhood predictors of adult disease. Pediatrics. 1998;101 (Supplement 2):518-25.

108. Touger-Decker R, Van Loveren C. Sugars and dental caries. Am J Clin Nutr. 2003;78(4):881S-92S.

109. Malik VS, Hu FB. Fructose and Cardiometabolic health: what the evidence from sugar-sweetened beverages tells us. J Am Coll Cardiol. 2015;66(14): 1615-24. https://doi.org/10.1016/j.jacc.2015.08.025.

110. Ruxton C. The suitability of caffeinated drinks for children: a systematic review of randomised controlled trials, observational studies and expert panel guidelines. J Hum Nutr Diet. 2014;27(4):342-57.

\section{Submit your next manuscript to BioMed Central and we will help you at every step:}

- We accept pre-submission inquiries

- Our selector tool helps you to find the most relevant journal

- We provide round the clock customer support

- Convenient online submission

- Thorough peer review

- Inclusion in PubMed and all major indexing services

- Maximum visibility for your research

Submit your manuscript at www.biomedcentral.com/submit 